\title{
Uso de técnicas laboratoriais na avaliação de sistemas de produção de ruminantes em ambientes semiáridos
}

\author{
Use of laboratory techniques in the evaluation of ruminant production systems in semi-arid \\ environments
}

Uso de técnicas de laboratorio en la evaluación de sistemas de producción de rumiantes en ambientes semiáridos

Recebido: 03/03/2021 | Revisado: 12/03/2021 | Aceito: 14/03/2021 | Publicado: 21/03/2021

\author{
Girlene Cordeiro de Lima Santos \\ ORCID: https://orcid.org/0000-0002-6979-6321 \\ Universidade Federal da Paraíba, Centro de Ciências Agrárias, Brasil \\ E-mail: girlenecordeiross@gmail.com \\ Ana Maria Duarte Cabral \\ ORCID: https://orcid.org/0000-0002-6101-1104 \\ Universidade Federal Rural de Pernambuco, Brasil \\ E-mail: amdcabral@gmail.com
}

\begin{abstract}
Resumo
A escolha do tipo de sistema de produção animal é um fator importante, não apenas quando se trata da disponibilidade de alimentos para os animais, mas também pelos impactos que esta atividade pode causar ao meio ambiente. O semiárido do Nordeste brasileiro, possui médias anuais de temperatura de 23 a $27^{\circ} \mathrm{C}$ e clima quente e seco com precipitações pluviométricas entre 280 a $800 \mathrm{~mm}$. Essas condições edafoclimáticas entravam a pecuária regional, dado que, grande parte do rebanho é criado em manejo extensivo com principal fonte alimentar oriunda das plantas da Caatinga. Por isso, faz-se necessário, estudos de sistemas de produção adaptados a esses ambientes, garantindo a alimentação dos animais, sobretudo diante dos cenários de aquecimento global. Nessa perspectiva, por meio da composição química dos alimentos, as técnicas laboratoriais são as mais utilizadas para esse fim, favorecendo a escolha da forrageira capaz de melhorar a eficiência alimentar do animal, além de permitir conhecer a parcela de contribuição da mesma para a produção de metano $\left(\mathrm{CH}_{4}\right)$ entérico em animais ruminantes. Já que, dependendo do alimento, as bactérias metanogênicas do rúmen podem intensificar a produção de $\mathrm{CH}_{4}$. Portanto, equipamentos e métodos laboratoriais são continuamente recorridos na preparação de soluções e na condução de análises químicas de alimentos. Diante do exposto, objetivou-se descrever etapas de técnicas laboratoriais utilizadas na avaliação de sistemas de produção de ruminantes em ambientes semiáridos.
\end{abstract}

Palavras-chave: Preparo de soluções; Determinação de FDN; Determinação de FDA; Determinação da DIVMS.

\begin{abstract}
The choice of the type of animal production system is an important factor, not only when it comes to the availability of food for the animals, but also because of the impacts that this activity can cause to the environment. The semi-arid region of the Brazilian Northeast has annual temperature averages of 23 to $27^{\circ} \mathrm{C}$ and a hot, dry climate with rainfall of 280 to $800 \mathrm{~mm}$. These edaphoclimatic conditions hinder regional livestock farming, given that a large part of the herd is raised in extensive management with the main food source coming from Caatinga plants. Therefore, it is necessary to study production systems adapted to these environments, ensuring the feeding of animals, especially in the face of global warming scenarios. In this perspective, through the chemical composition of food, laboratory techniques are the most used for this purpose, favoring the choice of forage capable of improving the feed efficiency of the animal, besides allowing the knowledge of its contribution to the production of enteric methane $\left(\mathrm{CH}_{4}\right)$ in ruminant animals. Since, depending on the feed, methanogenic bacteria in the rumen can intensify $\mathrm{CH}_{4}$ production. Therefore, laboratory equipment and methods are continuously resorted to in preparing solutions and conducting chemical analyses of feed. In view of the above, this study aimed to describe the steps of laboratory techniques used in the evaluation of ruminant production systems in semi-arid environments.
\end{abstract}

Keywords: Preparation of solutions; Determination of NDF; Determination of ADF; Determination of IVDMD.

\section{Resumen}

La elección del tipo de sistema de producción animal es un factor importante, no sólo por la disponibilidad de alimentos para los animales, sino también por los impactos que esta actividad puede causar en el medio ambiente. La región semiárida del nordeste brasileño tiene temperaturas medias anuales de 23 a $27^{\circ} \mathrm{C}$ y un clima cálido y seco, con 
precipitaciones de 280 a $800 \mathrm{~mm}$. Estas condiciones edafoclimáticas dificultan la ganadería regional, dado que, gran parte del rebaño se cría en régimen extensivo con la principal fuente de alimentación derivada de las plantas de la Caatinga. Por lo tanto, es necesario estudiar sistemas de producción adaptados a estos entornos, que garanticen la alimentación de los animales, especialmente ante los escenarios de calentamiento global. En esta perspectiva, a través de la composición química de los alimentos, las técnicas de laboratorio son las más utilizadas para este fin, favoreciendo la elección de forrajes capaces de mejorar la eficiencia alimentaria del animal, además de permitir conocer la parte de su contribución a la producción de metano $\left(\mathrm{CH}_{4}\right)$ entérico en los rumiantes. Ya que, dependiendo del alimento, las bacterias metanogénicas en el rumen pueden intensificar la producción de $\mathrm{CH}_{4}$. Por ello, se recurre continuamente a equipos y métodos de laboratorio para preparar soluciones y realizar análisis químicos de los alimentos. Teniendo en cuenta lo anterior, el presente estudio tiene como objetivo describir las etapas de las técnicas de laboratorio utilizadas en la evaluación de los sistemas de producción de rumiantes en ambientes semiáridos.

Palabras clave: Preparación de soluciones; Determinación de FDN; Determinación de FDA; Determinación de DIVMS.

\section{Introdução}

O Nordeste possui 1,56 milhão de $\mathrm{km} 2$, o que representa $18 \%$ do território brasileiro. Por sua vez, o semiárido representa $70 \%$ desta extensão, a qual possui médias anuais de temperatura de 23 a $27^{\circ} \mathrm{C}$, com evaporação de 2.000 mm ao ano e 50\% de média de umidade (Moura et al., 2007). De acordo com Araújo (2011), o semiárido brasileiro possui clima quente e seco com precipitações pluviométricas entre 280 a $800 \mathrm{~mm}$. A estação chuvosa dura em torno de 3 a 5 meses e o período seco por volta 7 a 9 meses. $80 \%$ dos solos são predominantemente rasos com rochas cristalinas, que dificulta o acúmulo de água (Zanella, 2014). Essas condições edafoclimáticas entravam a pecuária regional, dado que, grande parte do rebanho é criado em manejo extensivo com principal fonte alimentar oriunda das plantas da Caatinga. Além disso, o elevado déficit hídrico, por causa das altas temperaturas e baixas chuvas, inibe em grande parte do ano a disponibilidade de alimentos (Silva et al., 2021). Por isso, faz-se necessário, estudos de sistemas de produção adaptados a esses ambientes com o objetivo de garantir a alimentação dos animais, sobretudo diante dos cenários de aquecimento global. Especialmente nas regiões mais vulneráveis ao aquecimento global, como o Nordeste brasileiro, uma vez que boa parte de sua extensão é formada por ambiente semiárido (Silva et al., 2008; Silva et al., 2019; Santos \& Cabral, 2021).

A escolha do tipo de sistema de produção é um fator importante, não apenas quando se trata da disponibilidade de alimentos, mas também pelos impactos que esta atividade pode causar ao meio ambiente (Oliveira et al., 2021). Por esse motivo, diversas pesquisas vêm sendo conduzidas para melhorar o uso desses sistemas e, torná-los altamente sustentável (Santos et al., 2020; Cabral et al., 2020; Garcia et al., 2020).

De acordo com o regime alimentar, os sistemas de produção animal podem ser: extensivo (sistema apenas com pastagens nativas e cultivadas); semi-intensivo (pastagens nativas e cultivadas com suplementos minerais, proteico-energéticos a pasto); e, intensivo (pastagens com suplementação e confinamento) (Cezar et al., 2005; Guimarães et al., 2020).

Outras opções sustentáveis são os sistemas agroflorestais (SAFs) (Silva et al., 2021), que de acordo Machado, Balbino e Ceccon (2011), o uso da terra, as árvores, a agricultura e, ou, animais possuem uma comunicação ecológica ajustada entre as atividades que o compõem. Neste tipo de sistema, têm-se as seguintes derivações: agropastoril (agricultura e pecuária); silvipoastoril (floresta e pecuária); agrossilviculturais ou silviagrícolas (agricultura e floresta); e agrossilvipastoris (agricultura, floresta e pecuária). Machado, Balbino e Ceccon (2011), ainda citam que esses sistemas podem ser também classificados como: interação lavoura-pecuária ou agropastoril; interação lavoura, pecuária, floresta ou agossilvipastoris; interação pecuáriafloresta ou silvispastoril; e interação lavoura-pecuária-floresta ou silviagricola. O sistema de integração lavoura pecuáriafloresta (ILPF) utiliza-se de pecuária e agricultura associados à vegetação arbórea (Figueiredo \& Oliveira, 2015), de tal forma que beneficia o estado físico de consistência e porosidade do solo e o acúmulo de carbono orgânico quando comparado aos sistemas convencionais e/ou de floresta secundária (Sales et al., 2018).

Considerando que para cada tipo de ambiente, os diversos sistemas de produção se comportam de distintas maneiras, 
por causa das características climáticas, tipo de solo e manejo adotado, a avaliação contínua destes por meio de técnicas de acompanhamento do desempenho vegetal e animal é muito importante na tomada de decisão de qual sistema deve ser adotado (Gondim Filho et al., 2020; Peixoto et al., 2020). Nessa perspectiva, o uso de técnicas laboratoriais utilizadas para avaliação nutricional do alimento, além de favorecer a escolha de uma dieta capaz de melhorar a eficiência alimentar do animal em um determinado ambiente, também permite saber a parcela de contribuição da mesma para a produção de metano $\left(\mathrm{CH}_{4}\right)$ entérico pelos animais ruminantes (Oliveira et al., 2021).

$\mathrm{O}$ gás $\mathrm{CH}_{4}$, é um dos principais gesses do efeito estufa, sendo o mais associado à pecuária, em razão de ser produzido através do processo fermentativo do rúmen em ruminantes. Portanto, conhecer a composição química do alimento, é uma estratégia importante na mitigação $\mathrm{CH}_{4}$, já que, dependendo do tipo de alimento, as bactérias Archaeas metanogênicas durante a degradação dos carboidratos podem intensificar ou reduzir a produção de $\mathrm{CH}_{4}$ no rúmen (Moura et al., 2015; Oliveira et al., 2021). Além disso, durante a produção de $\mathrm{CH}_{4}$, há também perdas de energia pelo animal (Pedreira et al., 2004). Logo, é importante a formulação de dietas que minimizem a emissão de gases, e que não impactem na produção e no retorno econômico ao produtor (Salman et al., 2010; Oliveira et al., 2021). Neste sentido, análises químicas de alimentos, é uma das técnicas laboratoriais mais utilizadas para esse fim, uma vez que, permite conhecer a composição nutricional do alimento, visando a melhor escolha no momento da oferta ao animal (Beraldo \& Araújo, 2017); e, por meio da técnica da digestibilidade in vitro da matéria seca (DIVMS), permite avaliar a digestibilidade do alimento, ou seja, quanto o animal consegue aproveitar de um determinado alimento, como exemplo, as forragens presentes em diferentes sistemas de produção animal (Goes, 2010).

Com base no exposto, objetivou-se descrever etapas de técnicas laboratoriais utilizadas na avaliação de sistemas de produção de ruminantes em ambientes semiáridos.

\section{Metodologia}

Esse trabalho foi realizado por meio de uma abordagem descritiva qualitativa e apoiada por uma revisão de literatura sobre o tema do estudo (Koche, 2011; Ludke \& Andre, 2013; Pereira et al., 2018).

O trabalho tem como objetivo detalhar o passo a passo do preparo de soluções utilizadas em análises químicas laboratoriais de alimentos, empregadas na avaliação de sistemas de produção de ruminantes em ambientes semiáridos do Nordeste brasileiro.

Todos os passos mencionados nesse estudo foram baseados nas metodologias de Tlley e Terry (1963), Van Soest e Moore (1966), Van Soest (1967) e Kjeldahl (A.O.A.C., 1984), sugeridas por Silva e Queiroz (2002).

$\mathrm{O}$ estudo foi dividido em duas etapas. Na primeira, são descritos os equipamentos, materiais e reagentes utilizados para o preparo das seguintes soluções: solução de ácido bórico (H3BO3) a 2\%; solução de hidróxido de sódio (NaOH) a 50\%, solução para determinação de fibra em detergente neutro (FDN); solução para determinação de fibra em detergente ácido (FDA); e, solução para determinação de lignina. As soluções abordadas nesta primeira etapa são necessárias para a realização das análises químicas descritas na etapa posterior.

$\mathrm{Na}$ segunda etapa, foram detalhados os passos necessários para as seguintes análises químicas de alimentos: determinação da matéria seca em duas etapas (Pré-secagem a $55^{\circ} \mathrm{C}$ e determinação de matéria seca a $105^{\circ} \mathrm{C}$ ); determinação da matéria mineral (\%MM) e da matéria orgânica (\%MO); determinação de FDN; determinação de FDA; determinação da proteína bruta (dosagem de nitrogênio total); e, determinação de DIVMS. 


\section{Preparo de Soluções}

\section{Solução de ácido bórico (H3BO3) a $2 \%$}

Equipamentos: 01 agitador de soluções AP59, 01 agitador magnético e 01 balança com precisão de 0,0001 g. Materiais: 02 balões volumétricos de $2.000 \mathrm{ml}$ e 01 Becker de $4.000 \mathrm{ml}$.

Reagentes: $40 \mathrm{~g}$ de ácido bórico, $1.200 \mathrm{ml}$ de água, $12 \mathrm{ml}$ de verde bromocresol a 0,1\% e $30 \mathrm{ml}$ de vermelho de metil.

Preparo: Inicialmente, pesa-se $40 \mathrm{~g}$ de ácido bórico e adiciona-o em um béquer de $2.000 \mathrm{ml}$ contendo $1.200 \mathrm{ml}$ de água para aquecimento e mistura da solução até dissolver. Após isso, adiciona-se $12 \mathrm{ml}$ de verde bromocresol a $0,1 \%$ e $30 \mathrm{ml}$ de vermelho de metila, antes preparados. Em seguida, transfere-se a solução para outro béquer de $2.000 \mathrm{ml}$ para esfriar, aferir, homogeneizar e armazenar em um novo recipiente para uso posterior.

\section{Solução de hidróxido de sódio $(\mathrm{NaOH})$ a $50 \%$}

Equipamentos: 01 bloco digestor com temperatura controlada até $400^{\circ} \mathrm{C}$.

Materiais: 01 béquer de $4.000 \mathrm{ml} \mathrm{e} 01$ bastão de vidro.

Reagentes: $2.000 \mathrm{ml}$ de água e $1.000 \mathrm{~g}$ de hidróxido de sódio.

Preparo: mede-se $2.000 \mathrm{ml}$ de água e a transfere para um béquer de $4.000 \mathrm{ml}$. Em seguida, na capela, acrescenta-se $1.000 \mathrm{~g}$ de hidróxido de sódio, mexendo com um bastão de vidro, espera esfriar, para então, guardar em novo recipiente para posterior uso.

\section{Solução para determinação de FDN}

Equipamentos: 01 agitador magnético e 01 balança de precisão de 0,0001g.

Materiais: 01 becker de $1.000 \mathrm{ml}, 01$ balão volumétrico de $1.000 \mathrm{ml}, 01$ bastão de vidro, 01 barra magnética e 01 pisseta.

Reagentes: $1 \mathrm{~L}$ de água destilada, $30 \mathrm{~g}$ de lauril sulfato de sódio, $10 \mathrm{ml}$ de etileno glicol, 18,60 g de EDTA de sódio (2H20), $6,81 \mathrm{~g}$ de borato de sódio (10H20) e 4,56 g de fosfato de sódio anidro.

Preparo: primeiro, pesa-se individualmente, todos os reagentes em distintos recipientes, para em seguida, adicioná-los em um béquer de $1.000 \mathrm{ml}$ contendo $400 \mathrm{ml}$ de água morna destilada. Posteriormente, para remoção dos resíduos dos reagentes nos recipientes, todos devem ser lavados com auxílio de uma pisseta, usando água destilada. Em seguida, mexe-se a solução cuidadosamente e coloca-se a solução em balão volumétrico de $1.000 \mathrm{ml}$, para então, agitar e deixar em repouso para que os reagentes possam reagir.

\section{Solução para determinação de FDA}

Equipamentos: 01 agitador magnético, 01 balança de precisão de 0,0001g e 01 bloco digestor com temperatura controlada até $400^{\circ} \mathrm{C}$.

Materiais: 01 becker de $1.000 \mathrm{ml}, 01$ balão volumétrico de 1.000ml, 01 bastão de vidro e 01 barra magnética.

Reagentes: ácido sulfúrico (H2SO4) e Cetil trimetil amônio brometo (CTAB).

Preparo: Para preparação da solução, adiciona-se, em um béquer de $1.000 \mathrm{ml}$ com $500 \mathrm{ml}$ de água, 28,5 ml de ácido sulfúrico medido por meio de uma proveta de $100 \mathrm{ml}$. Posteriormente, pesa-se 20,4 g de Cetil trimetil amônio brometo (CTAB) e o transfere lentamente para o béquer que já possuí uma solução de H2SO4. Em seguida, esta solução deverá ser colocada em balão volumétrico de $1.000 \mathrm{ml}$ para medição, agitação e repouso visando a interação entre os reagentes. Esse procedimento deve ser feito em ambiente de exaustão forçada, utilizando luvas e máscara. 


\section{Solução para determinação de lignina}

Materiais: béquer de vidro, blocos de gelo e bandeja.

Reagentes: $415 \mathrm{ml}$ de água destilada e $663 \mathrm{ml}$ de ácido sulfúrico concentrado (H2SO4).

Preparo: Na elaboração desta solução, coloca-se $415 \mathrm{ml}$ de água destilada para congelar em um béquer de vidro. Posteriormente, o béquer com a água congelada deve ser acomodado em uma bandeja contendo água e blocos de gelo e aos poucos, deve-se ir adicionando $663 \mathrm{ml}$ de ácido sulfúrico sem deixar a água ferver. Deve-se esperar uma hora para poder usar a solução, sendo que para cada saco de amostra utiliza-se $10 \mathrm{ml}$ da solução.

\section{Condução de Análises Químicas de Alimentos}

\section{Determinação da matéria seca em duas etapas}

Pré-secagem a $55^{\circ} \mathrm{C}$

Nesta etapa de pré-secagem, denominada ASA (amostra seca ao ar), o objetivo é remover parcialmente a quantidade de água presente na matéria verde. A sua determinação é necessária para a condução das demais análises químicas (proteína bruta, extrato etéreo, carboidratos estruturais e matéria mineral). Nas dietas de ruminantes, a MS pode variar de 10 a $80 \%$ (Medeiros, Gomes \& Bungenstab, 2015). Este método será descrito de acordo com a metodologia mencionada por Silva e Queiroz (2002), detalhada a seguir, em que utiliza equipamentos, materiais e procedimentos, a saber:

Equipamentos: estufa de secagem de ar forçado (Temperatura de $55^{\circ} \mathrm{C}$ ), balança analítica com precisão de aproximadamente de $0,0001 \mathrm{~g}$ e moinho Wiley de facas com peneira de $1 \mathrm{~mm}$.

Materiais: Saco de papel perfurado $(5 \mathrm{~kg})$ ou bandejas metálicas $(22 \times 16 \times 6 \mathrm{~cm})$.

Procedimento: Primeiramente, o peso do saco de papel ou com bandeja metálica deverá ser tarado na balança, a depender do material vegetal. Em seguida, coloca-se no saco de papel ou bandeja metálica, uma amostra de matéria natural, e a mesma precisa ser pesada, obtendo-se cerca de 250 g por repetição. Depois, o conjunto (saco mais amostra) será inserido dentro de uma estufa de circulação forçado de ar com $55^{\circ}$ a $60^{\circ} \mathrm{C}$ por 48 a $72 \mathrm{~h}$. Após esse período, retira-se o material da estufa, deixando-a de 30 a 40 min à temperatura do ambiente, para então, pesar e anotar o peso em ficha específica. Em seguida, o material vegetal será moído em moinho de facas e, uma subamostra de 50 g será armazenada em sacos plásticos devidamente identificados. Sempre após essa etapa de moagem, o moinho necessita ser cuidadosamente limpo.

Com a tabulação dos resultados, os seguintes cálculos devem ser realizados:

$$
\begin{gathered}
M N=(T+M N)-T \\
A S A=(T+A S A)-T \\
\text { \%ASA }=\frac{A S A}{M N} x 100
\end{gathered}
$$

em que,

$\%$ ASA = percentual de amostra seca ao ar;

$\mathrm{MN}$ = massa da amostra em termos de matéria natural, ou seja, massa fresca (g);

ASA = massa de amostra seca em equilíbrio com a umidade relativa do ar (g);

$\mathrm{T}=$ tara o peso do recipiente ou saco utilizado $(\mathrm{g})$.

\section{Determinação de matéria seca a $105^{\circ} \mathrm{C}$}

Esta etapa representa a ASE (amostra seca em estufa a $105^{\circ} \mathrm{C}$ ), sendo necessária, uma vez que, mesmo com a pré- 
secagem da matéria verde a $55^{\circ} \mathrm{C}$ (ASA), a amostra ainda pode conter de 1 a $5 \%$ de água, logo, este procedimento tem como finalidade remover esse resíduo. Em alimentos com mais de $80 \%$ de MS, a ASA é dispensada (Medeiros, Gomes \& Bungenstab, 2015). Este método será mostrado a seguir conforme a metodologia de Van Soest (1967), descrito em Silva e Queiroz (2002), como segue:

Equipamentos: balança de precisão de $0,0001 \mathrm{~g}$, estufa a $105^{\circ} \mathrm{C}$ e mufla a $600{ }^{\circ} \mathrm{C}$.

Materiais: Cadinho de porcelana e Dessecador.

Procedimentos: Antes de iniciar a determinação da ASE, coloca-se cadinhos vazios em estufa a $105{ }^{\circ} \mathrm{C}$ durante $2 \mathrm{~h}$ e, $\operatorname{logo}$ depois mais 40 min em um dessecador. Então, os cadinhos secos são pesados individualmente e, $2 \mathrm{~g}$ de amostra serão adicionadas, para depois seguirem para estufa a $105^{\circ} \mathrm{C}$, por uma noite ou $12 \mathrm{~h}$. Posteriormente, coloca-se novamente os cadinhos no dessecador por 40 min, para depois pesar em balança analítica e anotar do peso em ficha específica.

Semelhante a ASA, na ASE procede-se aos seguintes cálculos:

$$
M S \%=100-((P C A-P C)-(P C A S-P C)) \times 100
$$

onde,

PCA = peso do cadinho com a amostra;

$\mathrm{PC}=$ peso do cadinho;

PCAS = peso do cadinho com a amostra.

Combinando a ASA e ASE, obtêm-se:

$$
M S(\%)=(\% A S A x \% A S E) / 100
$$

\section{Determinação da matéria mineral (\%MM) e da matéria orgânica (\%MO)}

A MM é a porção resultante da amostra aquecida de 500 a $600^{\circ} \mathrm{C}$ durante $4 \mathrm{~h}$ até a queima total da MO, disponibilizando apenas uma indicação dos minerais contidos na amostra (Rodrigues, 2010). A MM contém especialmente os cátions (cálcio, potássio, sódio, magnésio, ferro, cobre, cobalto e alumínio) e ânions (sulfato, cloreto, silicato, fosfato, entre outros) (Rodrigues, 2010). Quando se trata de amostra vegetal, a MM indica poucas informações sobre seus componentes (Beraldo \& Araújo, 2017). A MM e a MO podem ser obtidas seguindo as etapas descritas por Silva e Queiroz (2002), a saber: Equipamentos: balança de precisão de $0,0001 \mathrm{~g}$ e forno mufla a $600{ }^{\circ} \mathrm{C}$.

Materiais: cadinho de porcelana e dessecador.

Procedimentos: o material dentro do cadinho dever ser incinerado em mufla a $600{ }^{\circ} \mathrm{C}$, por $4 \mathrm{~h}$. Após isto, a mufla precisa ser desligada, e aguardar até que a mesma atinja temperatura de $10{ }^{\circ} \mathrm{C}$ para retirar os cadinhos. Os mesmos devem ser colocados em dessecador por 40 min e depois pesados para obtenção da MM, seguindo os cálculos:

$$
\begin{gathered}
M M=(C A D+M M)-C A D \\
\% \mathrm{MM}=\frac{M M}{A S A} \times 100 \\
\% \mathrm{MM}=\frac{M M}{\% A S E} \times 100
\end{gathered}
$$


onde,

$\mathrm{MM}=$ peso do cadinho e o peso da cinza;

$\mathrm{CAD}=$ peso do cadinho.

A partir dos valores de \%MM, obtêm-se o \%MO:

$$
\% M O=100-\% \text { Cinzas }
$$

Corrigido para $100 \%$ da MS, tem-se:

$$
\text { Base seca }=\frac{\% M O}{\% M S} \times 100
$$

onde,

$\% \mathrm{MO}=\%$ de matéria orgânica na amostra;

$\% \mathrm{MS}=\%$ de MS na amostra a $105^{\circ} \mathrm{C}$.

\section{Determinação da fibra em detergente neutro}

A fibra compõe a parede celular dos vegetais. FDN é o resultado da fibra insolúvel do alimento, sendo indicador de consumo e digestibilidade na caracterização de dietas de ruminantes (Macedo Júnior et al., 2007; Rodrigues, 2010). Rodrigues (2010) e Salman et al. (2010), citam que a parte solúvel em detergente neutro é composta por nitrogênio (N) ligado a fibra, nitrogênio não proteico (NNP), proteína, lipídios, açúcares, pigmentos, ácidos orgânicos e pectina.

Diferente da FDA, que é formada, principalmente por celulose, hemicelulose e lignina. Para cada $1000 \mathrm{~g}$ de fibra, 733 g é de FDN, ou seja, 7,33 \% da matéria seca (MS) do alimento é parte fibrosa (Medeiros, Gomes \& Bungenstab, 2015).

O método usado para determinação da FDN, detalhado nesse estudo foi proposto por Van Soest \& Robrtson (1985), conforme descrito em Silva e Queiroz (2002), como segue:

Equipamentos: 01 estufa de secagem a $105^{\circ} \mathrm{C}$ e um determinador de fibra.

Materiais: Sacos de tecido TNT gramatura de 100, 02 béqueres de $1.000 \mathrm{ml}, 01$ Dessecador e 01 espremedor de queijo. Soluções: solução de FDN, água destilada, enzima amilase termamyl e acetona P.A (C3H60) 99,5\%.

Preparo: Incialmente, para a confecção dos sacos, corta-se um tecido TNT em pedaços de $10 \mathrm{~cm}$ de comprimento e $5 \mathrm{~cm}$ de largura. Estes pedaços de TNT cortados são fechados usando uma máquina seladora, formando pequenos sacos. Em seguida os socos são numerados e levados para estufa a $105^{\circ} \mathrm{C}$ por $2 \mathrm{~h}$, e depois ficam mais 40 min no dessecador, para então pesagem. 0,5 g da amostra será colocada em cada saco, o qual será fechado com o auxílio de uma seladora. Em seguida, os sacos lacrados são inseridos nas galerias do determinador de fibra. Neste equipamento devem ser colocados $2 \mathrm{~L}$ da solução de detergente neutro e 30 gotas da enzima amilase termamyl 2x. Depois de posicionadas as amostras no equipamento, a torneira de água do equipamento deve ser aberta e o mesmo ligado até atingir $100^{\circ} \mathrm{C}$. O temporizador deverá ser acionado por 60 min e, em seguida, o equipamento precisa ser desligado. Os sacos necessitam ser retirados das galerias do determinador de fibra e acomodados em uma peneira (tipo espremedor) para lavagem com água corrente. Em seguida, os sacos são espremidos cuidadosamente para retirar o excesso de água, e colocados em béquer com água destilada com 90 a $100^{\circ} \mathrm{C}$ por $10 \mathrm{~min}$. Este procedimento será repetido por mais duas vezes, para então colocar os sacos em um béquer com acetona P.A (C3H60) a 99,5\% de pureza durante $5 \mathrm{~min}$. $\mathrm{O}$ excesso de acetona dos sacos deve ser retirado e os mesmos deixados em bancada em uma bandeja 
por $2 \mathrm{~h}$. Em seguida, os sacos são levados para estufa a $55^{\circ} \mathrm{C}$ por $24 \mathrm{~h}$, seguidos para estufa a $105^{\circ} \mathrm{C}$ durante $2 \mathrm{~h}$ e dessecador por mais 40 min, para então, pesagem e anotação dos resultados em planilha.

Posteriormente, os seguintes cálculos são procedidos:

$$
\% \mathrm{FDN}=\frac{[(T+F D N)-T] x 100}{A S E}
$$

Corrigido para cinzas:

$$
\% \mathrm{FDN}=[((\mathrm{T}+\mathrm{FDN})-\mathrm{T}))-(\mathrm{T}+\text { Cinza })-\mathrm{T}] \times 100
$$

onde,

$\mathrm{T}=$ tara ou peso do recipiente ou saco utilizado $(\mathrm{g})$.

\section{Determinação da fibra em detergente ácido}

A FDA é a parte menos digestível da parede celular dos alimentos, formada, sobretudo por lignina e celulose. A lignina é o primeiro fator antinutricional nas dietas de ruminantes, mesmo não sendo um carboidrato, faz parte da parede celular do vegetal. Já a celulose é a parte solúvel em detergente ácido, sendo obtida da diferença entre FDN e FDA (Medeiros, Gomes \& Bungenstab, 2015; Rodrigues, 2010; Silva \& Queiroz, 2002). No percentual da MS do alimento é aceita até $21 \%$ de FDA presente na dieta (Rodrigues, 2010).

A metodologia de Van Soest e Robrtson (1985) citada em Silva e Queiroz (2002), para a determinação de FDA, será mostrada a seguir:

Equipamentos: 01 determinador de fibra.

Materiais: 02 béqueres de $1.000 \mathrm{ml}, 01$ Dessecador e 01 espremedor de queijo.

Soluções: solução de FDA, água destilada, e acetona P.A (C3H60) 99,5\%.

Preparo: este procedimento é semelhante ao da determinação de FDN. Nesta etapa, o resíduo da amostra utilizada na determinação da FDN é colocado novamente no determinador de FDN/FDA, no qual ainda serão adicionados 2 L de solução de detergente ácido. Depois de fechado o equipamento, a torneira de água precisa ser aberta, a chave geral do equipamento ligada, e quando atingir $100^{\circ} \mathrm{C}$, o temporizador será acionado por $60 \mathrm{~min}$. Após esse tempo, desliga-se o determinador, retira-se a galeria e as amostras devem ser colocadas em peneira (tipo espremedor) para lavar com água corrente e depois deve-se espremê-los para retirar o excesso de água. Em seguida, os sacos são colocados em um béquer com água destilada com temperatura de 90 a $100^{\circ} \mathrm{C}$, por $10 \mathrm{~min}$; posteriormente, retira-se o excesso de água, repetindo o procedimento por mais duas vezes, para então, colocar os sacos em um beque com acetona P.A (C3H60) a 99,5\% de pureza durante 5 min. Depois, o excesso de acetona dos sacos é removido e, os mesmos deixados na bancada em uma bandeja por $2 \mathrm{~h}$. Em seguida, os sacos precisam ser levados para estufa a $55^{\circ} \mathrm{C}$ por $24 \mathrm{~h}$, para estufa a $105^{\circ} \mathrm{C}$ durante $2 \mathrm{~h}$, seguidos para o dessecador por mais 30 min, para então pesagem e anotação dos resultados em planilha.

Posteriormente, procede-se com os seguintes cálculos:

$$
\% \mathrm{FDA}=\frac{(T+F D A)-T \times 100}{A S E}
$$


Corrigido para cinzas:

$$
\% \mathrm{FDA}=[((\mathrm{T}+\mathrm{FDA})-\mathrm{T}))-(\mathrm{T}+\text { Cinza })-\mathrm{T}] \times 100
$$

\section{Determinação da proteína bruta (dosagem de nitrogênio total)}

Essa análise foi conduzida em três etapas: digestão, destilação e titulação. Na digestão, o nitrogênio orgânico é convertido em amônia, e esta é recebida em uma solução receptora durante a destilação, e assim quantificada (Rodrigues, 2010). A concentração de $\mathrm{N}$ do alimento $(\% \mathrm{~N})$ multiplicado por 6,25 é igual à proteína bruta total presente (Medeiros, Gomes \& Bungenstab, 2015).

Esse método, que é abordado a seguir, segue a metodologia de Kjeldahl (A.O.A.C., 1984), descrito em Silva e Queiroz (2002), conforme a sequência:

Equipamentos: 01 balança com precisão $0,0001 \mathrm{~g}, 01$ bloco digestor com temperatura controlada até $400^{\circ} \mathrm{C}, 01$ agitador de soluções AP59, 01 agitador magnético, 01 destilador de Nitrogênio Kjeldahl, modelo TE-036/1 e 01 bureta volumétrica de 50 $\mathrm{ml}$.

Materiais: erlenmyer de $125 \mathrm{ml}$, tubos para digestão com borda de 25 x $250 \mathrm{~mm}, 01$ pisseta $500 \mathrm{ml}, 01$ proveta $100 \mathrm{ml}$ e 01 dispensador de solução $1000 \mathrm{ml}$.

Soluções: ácido sulfúrico (H2SO4), mistura catalisadora, ácido bórico (H3BO3) 2\%, ácido clorídrico (HCl) e hidróxido de Sódio $(\mathrm{NaOH})$ a $50 \%$.

Preparo: Para digestão, pesa-se $0,2 \mathrm{~g}$ de amostra e a adiciona em tubo de digestão para, na sequência acrescentar $2 \mathrm{~g}$ de mistura catalisadora e $5 \mathrm{ml}$ de ácido sulfúrico concentrado. O tubo deve ser inserido dentro do bloco digestor, o qual precisa ser regulado para aumentar a temperatura em $100^{\circ} \mathrm{C}$ a cada 30 min até atingir a temperatura de $350^{\circ} \mathrm{C}$. $\mathrm{O}$ aquecimento se prolonga por 3,5 h. Depois o bloco digestor é desligado. Na destilação, nos tubos já frios é adicionado $5 \mathrm{ml}$ de água destilada e os mesmos devem ser agitados para retirar a cristalização do sulfato de amônio. Logo depois, coloca-se $10 \mathrm{ml}$ de ácido bórico a $2 \%$ em um erlenmyer com capacidade de $125 \mathrm{ml}$, que deve ser acoplado no aparelho destilador. Em seguida, acopla-se o tubo com a amostra no destilador, coloca-se $15 \mathrm{ml}$ de hidróxido de sódio a 50\% no copo dosador e, em seguida, acrescenta-se água destilada para que o restante de hidróxido de sódio seja totalmente liberado. Em seguida, a torneira da água de circulação do condensador é aberta e o aquecimento do destilador é ligado. A solução de ácido bórico vermelha passa a verde pela presença de amônia. Apenas quando a solução atingir $75 \mathrm{ml}$, o erlenmyer deve ser levado para a titulação. Enfim, a titulação do destilado é feita com uma solução de ácido clorídrico a 0,02 M, adicionando-se doseadamente o ácido clorídrico e, ao mesmo tempo, realizando movimentos giratórios até atingir o ponto de viragem, que é do verde para o vermelho.

Então, os resultados da quantidade de ácido clorídrico utilizado são anotados em ficha específica para depois proceder aos seguintes cálculos:

$$
\% \mathrm{~N}=0,14 x f x \mathrm{Vm}
$$

Proteína Bruta: \%N x 6,25

onde,

$\mathrm{f}$ = fator de correção da normalidade do ácido;

$\mathrm{Vm}=$ volume médio do ácido clorídrico gasto com a amostra. 


\section{Determinação da digestibilidade in vitro da matéria seca}

A digestibilidade representa a qualidade do alimento, sendo expressa pela diferença do alimento ingerido e o que é excretado. A digestibilidade pode ser determinada para MS ou energia ou para as partes integrantes da matéria orgânica, como: PB, EE, ENN, fibra bruta ou FDN e FDA (Salman et al., 2010). Silveira et al. (2009), citam que a digestibilidade in vivo de dietas compostas de silagem e concentrados é capaz de ser estimada pelo método in vitro. A DIVMS, tem como objetivo simular, em laboratório, a degradação da MS em nível de rúmen-retículo. Durante esse processo, utiliza-se saliva artificial e líquido ruminal (inócuo) em tubos contendo amostras do alimento a ser avaliado por um período de $48 \mathrm{~h}$ a $39^{\circ} \mathrm{C}$. Este procedimento garante condições ideais para o desenvolvimento, manutenção e ação dos microrganismos ruminais, simulando assim as condições de um rúmen verdadeiro (Rodrigues, 2010; Silva \& Queiroz, 2002).

Este método é detalhadamente descrito a seguir, conforme metodologia de Tlley e Terry (1963), e modificada por Van Soest e Moore (1966), Van Soest e Robrtson (1985), de acordo Silva e Queiroz (2002), a saber:

Equipamentos: Incubador, bujão de C02 equipado com válvula de saída controlável, balança de precisão de 0,0001 g e estufa de secagem a $105^{\circ} \mathrm{C}$.

Materiais: Pano de queijo, garrafa térmica, proveta e dessecador.

Soluções: Saliva artificial com PH (6,8), pepsina e água destilada.

Inócuo: Liquido ruminal.

Preparo: Esse método é dividido em duas etapas. Na primeira, coleta-se o líquido ruminal de um bovino fistulado após $2 \mathrm{~h}$ sem comer e $1 \mathrm{~h}$ sem beber, alimentado com feno. O líquido é coletado, espremido em quatro camadas de pano e colocado em garrafa térmica até chegar ao laboratório. Dentro de uma incubadora, com uma proveta, adiciona-se $12 \mathrm{ml}$ do líquido ruminal no tubo e $10 \mathrm{ml}$ de saliva artificial em tubos com tampa conjugada a uma válvula de busen (adaptados com a mangueira de borracha na tampa do tubo), já contendo a amostra do alimento em sacos de tecido TNT. A temperatura da incubadora deve ser controlada a $39^{\circ} \mathrm{C}$. Os tubos deverão ser agitados para que o líquido consiga atingir toda amostra e, em seguida, é inserido $\mathrm{CO}_{2}$ dentro dos tubos com o objetivo de extrair do oxigênio do tubo. Com a rolha bem vedada e temperatura ambiente de $39^{\circ} \mathrm{C}$ por $48 \mathrm{~h}$, os tubos precisam ser agitados a cada $2 \mathrm{~h}$ ou 3 a 4 vezes ao dia para eliminar os gases formados (metano) e simular as condições no rúmen do animal in vivo. A segunda etapa ocorre após completar às $48 \mathrm{~h}$, adicionando-se $0,9 \mathrm{ml}$ de solução de pepsina já misturada ao HCL. No animal in vivo, o pepsinogênio produzido na parede do estômago só se torna ativo em meio ácido, por isso, utiliza-se o HCL. A pepsina tem como objetivo quebrar as proteínas, convertendo-as em aminoácidos, logo também promovendo a morte dos microrganismos, semelhante ao que ocorre in vivo. Após isto, é necessário aguardar 24 h, mexendo os tubos ocasionalmente, para posterior filtragem do líquido do tubo. Faz-se três lavagens das amostras dentro dos sacos com água morna destilada e, em seguida, as leva à estufa a $105^{\circ} \mathrm{C}$ por uma noite. No dia seguinte, os sacos devem ser colocados no dessecador por 40 min para posterior pesagem do saco com o resíduo e cálculo da porção da amostra dig estível. Para isso, os cálculos seguintes são conduzidos:

$$
\% \text { DIMS }=\frac{\text { MSi }- \text { MSind } x 100}{\text { MSi }}
$$

onde,

MSind $=$ M.Sr - M.Sbr;

MSi = matéria seca inicial;

MSind = matéria seca indigestível;

$\mathrm{MSr}=$ matéria seca residual; 
MSbr = matéria seca do branco.

Para ajustar a 100\% da MS, utiliza-se a fórmula:

$$
\text { Base seca }=\frac{\mathscr{\%} \text { do Resultado }}{A S E} \times 100
$$

onde,

$\%$ do resultado $=\%$ de digestibilidade na análise.

\section{Considerações Finais}

Diante das atuais discussões sobre o aquecimento global e a alta vulnerabilidade do Nordeste brasileiro, em especial do Semiárido, há uma grande demanda de informações sobre sistemas de produção de ruminantes neste tipo de ambiente. Considerando que para cada tipo de ambiente, os diversos sistemas de produção se comportam de distintas maneiras, por causa das características climáticas, tipo solo e manejo, a avaliação contínua destes, por meio do desempenho da vegetação e do animal, utilizando técnicas laboratoriais é de extrema importância na avaliação de sistemas de produção de ruminantes, ou seja, na tomada de decisão de qual sistema deve ser adotado.

Com o aumento dos gases do efeito estufa, observado nos últimos anos, há uma preocupação dos pecuaristas com a quantidade de metano emitido pela atividade. Logo, sugere-se trabalhos que, por meio de análises laboratoriais estimem a quantidade de metano emitido por ruminantes em diferentes sistemas de produção no Semiárido brasileiro.

\section{Agradecimentos}

Os autores agradecem à Coordenação de Aperfeiçoamento de Pessoal de Nível Superior (CAPES - Código Financeiro 001) pela bolsa de estudo.

\section{Referências}

Araújo, S. D. (2011). A região semiárida do nordeste do Brasil: questões ambientais e possibilidades de uso sustentável dos recursos. Rios Eletrônica-Revista Científica da FASETE, 5(5), 89-98.

Beraldo, A. A., \& de Araújo, S. L. (2009). Análise bromatológica dos alimentos consumidos pelo rebanho leiteiro do planalto Norte Catarinense-região de Canoinhas-SC. Ágora: revista de divulgação científica, 16(2.), 302-317.

Cabral, A. M. D., Carvalho, F. F. R., Santos, G. C. de L., Ferreira, J. C., Silva, M. J. M. S., Santos, G. R. A., \& Melo, N. D. (2020). Use of sugar cane to feed lactating dairy goats. Arquivo Brasileiro de Medicina Veterinária e Zootecnia, 72(6), 2297-2307.

Figueiredo, Z. N., \& Oliveira, T. C. De. (2015). Produção e manejo de silagens. In: Produção e Manejo de Bovinos de Corte, (org.). Oliveira Filho, A. de. Cuiabá: KCM Editora \& Distribuidora Ltda, 25-41.

Garcia, P. H. D. M. (2020). Valor nutricional da silagem de genótipos de milho e sorgo cultivados em duas densidades de semeadura. In: Nutrição e Produção Animal, (1a ed.), Org. Carlos Alexandre Oelke. Guarujá, SP: Científica Digital. p. 335- 359. ISBN:978-65-87196-42-8

Gondim Filho, A. G. C., Moreira, G. R., Gomes-Silva, F., Cunha Filho, M., Gomes, D. A., Ferreira, A. L., Costa, M. L. L. da., Ferreira, D. S. de A., Gonçalves, N. C., Gomes, S. P., Pimentel, P. G., Santos, A. L. P. dos., \& Amaral, L. S. (2020). Avaliação nutricional de genótipos de Amendoim forrageiro (Arachis pintoi) por técnicas multivariadas. Research, Society and Development, 9(8), e758986039. https://doi.org/10.33448/rsd-v9i8.6039

Goes, R. H. D. T., \& Lima, H. L. (2010). Técnicas laboratoriais na análise de alimentos. Coleção Cadernos Acadêmicos. Dourados: UFGD.

Guimarães, Y. L. F., Debortoli, E. D. C., Santos, J. D., \& Gopinger, E. (2020). Comportamento ingestivo de bovinos em diferentes sistemas de produção uma revisão sistemática de estudos científicos. Research, Society and Development, 9(10), e4859108705. https://doi.org/10.33448/rsd-v9i10.8705

Koche, J. C. (2011). Fundamentos de metodologia científica. Vozes.

Ludke, M. \& Andre, M. E . D. A. (2013). Pesquisas em educação: uma abordagem qualitativa. E.P.U. 
Macedo Júnior, G. de L., Zanine, A. de M., Borges, I., \& Pérez, J. R. O. (2007). Qualidade da fibra para a dieta de ruminantes. Ciência Animal, 17(1), 7-17.

Machado, L. A. Z., Balbino, L. C., \& Ceccon, G. (2011). Integração lavoura-pecuária-floresta. 1. Estruturação dos sistemas de integração lavourapecuária. Embrapa Agropecuária Oeste-Documentos (INFOTECA-E), 46, 46.

Medeiros, S. R. de., Gomes, R. D. C., \& Bungenstab, D. J. (2015). Nutrição de bovinos de corte: fundamentos e aplicações. Embrapa Gado de Corte-Livro técnico (INFOTECA-E).

Moura, A. M., Gonçalves, L. C., Ferreira, P. D. S., Côrtes, I. H. G., Cruz, D. S. G., Melgaço, F. P., Oliveira, J. P. da C. A., \& Diniz, T. H. F. (2007). Métodos para medir a emissão individual de metano por ruminantes. Nutri Time, 12(6), 4435-4440.

Moura, M. S. B. de., Galvincio, J. D., Brito, L. T. de L., Souza, L. S. B., Sá, I. I. S., \& Silva, T. G. F. da. (2007). Clima e água de chuva no Semi-Árido. In: Potencialidades da água de chuva no Semi-Árido brasileiro, Org. Brito, L. T. de L., Moura, M. S. B. de, \& Gama, G. F. B. Petrolina, PE: Embrapa Semiárido, p. $37-59$.

Oliveira, J. F. F. de., Andrade, A. P. de., Valença, R. de L., Cunha, G. L. C. da., Araújo, F. dos S., \& Magalhães, A. L. R. . (2021). Metabólitos secundários presentes na palma forrageira: benefícios e potencialidades. Research, Society and Development, 10(2), e53910212809. https://doi.org/10.33448/rsdv10i2.12809

Pedreira, M. D. S., Berchielli, T. T., Oliveira, S. G. de., Primavesi, O., Lima, M. A. de., \& Frighetto, R. (2004). Produção de metano e concentração de ácidos gráxos voláteis ruminal em bovinos alimentados com diferentes relações de Volumoso: Concentrado. Embrapa Meio Ambiente-Artigo em anais de congresso (ALICE). In: Reunião Anual Da Sociedade Brasileira De Zootecnia, 41., 2004, Campo Grande, MS. A produção animal e a segurança alimentar: anais dos simpósios e dos resumos. Campo Grande, MS: Sociedade Brasileira de Zootecnia: Embrapa Gado de Corte, 2004. 1 CD-ROM.

Peixoto, R. M., Pinedo, L. A., Rosário, I. J. do., Oliveira, P. V. C. de., Ribeiro, A. A., Borges, L. da S., Santos, B. R. C. dos., Amorim, D. S., \& Chacón, S. G. (2020). Bromatologia da silagem de capim elefante com torta de cupuaçu em diferentes períodos de armazenamento. Research, Society and Development, 9(9), e644997789. https://doi.org/10.33448/rsd-v9i9.7789

Pereira, A. S. et al. (2018). Metodologia da pesquisa científica. UFSM.

Rodrigues, R. C. (2010). Métodos de análises bromatológicas de alimentos: métodos físicos, químicos e bromatológicos. Embrapa Clima TemperadoDocumentos (INFOTECA-E).

Sales, A., Silva, A. R., Veloso, C. A. C., Carvalho, E. J. M., \& Miranda, B. M. (2018). Carbono orgânico e atributos físicos do solo sob manejo agropecuário sustentável na Amazônia Legal. Colloquium Agrariae, 14(1), 01-15.

Salman, A. K., Ferreira, A. C. D., Soares, J. P. G., \& de Souza, J. P. (2010). Metodologias para avaliação de alimentos para ruminantes domésticos. Embrapa Rondônia-Documentos (INFOTECA-E).

Santos, G. C. de L., \& Cabral, A. M. D. (2021). Índices bioclimáticos, modelagem matemática e índices estatísticos para avaliação de modelos utilizados na estimativa do conforto térmico animal. Research, Society and Development, 10(3), e20910313328. https://doi.org/10.33448/rsd-v10i3.13328

Santos, G. C. L., Garcia, P. H. de M., Viana, T. B. L., Borges, P. F., Araujo, L. S., \& Gonzaga Neto, S. (2020). Crescimento e eficiência do uso da água do sorgo sob distintos regimes hídricos contínuos. Archivos de zootecnia, 69(265), 164-171.

Silva, D. F. da., Garcia, P. H. de M., Santos, G. C. de L., Farias, I. M. S. C. de., Pádua, G. V. G. de., Pereira, P. H. B., Silva, F. E. da., Batista, R. F., Gonzaga Neto, S., \& Cabral, A. M. D. (2021). Características morfológicas, melhoramento genético e densidade de plantio das culturas do sorgo e do milho: uma revisão. Research, Society and Development, 10(3), e12310313172. https://doi.org/10.33448/rsd-v10i3.13172

Silva, D. J., \& Queiroz, A. C. de. (2002). Análise de alimentos: métodos químicos e biológicos. UFV.

Silva, J. C. da., Kubiak, K. L., Zarzicki, L. F. W., Donazzolo, J., \& Tessaro, D. (2020). Diversidade morfológica de colêmbolos em sistemas agroflorestais no Sudoeste do Paraná. Research, Society and Development, 9(6), e184963606. https://doi.org/10.33448/rsd-v9i6.3606

Silva, T. G. F. da., Santos, G. C. de L., Duarte, A. M. C., Turco, S. H. N., Cruz Neto, J. F. da., Jardim, A. M. D. R. F., \& Santos, T. S. dos. (2019). Black globe temperature from meteorological data and a bioclimatic analysis of the Brazilian Northeast for Saanen goats. Journal of thermal biology, 85, 102408.

Silva, T. G. F. da., Turco, S. H. N., Zolnier, S., Soelma, M., Moura, B. de., \& Sá, I. I. S. (2008). Variação regional do declínio na produção de leite durante o verão no estado de pernambuco. Engenharia na Agricultura, 16(1), 109-123.

Silveira, M. F., Kozloski, G. V., Mesquita, F. R., Farenzena, R., Senger, C. C. D., \& Brondani, I. L. (2009). Avaliação de métodos laboratoriais para estimar a digestibilidade e o valor energético de dietas para ruminantes. Arquivo Brasileiro de Medicina Veterinária e Zootecnia, 61(2), $429-437$.

Zanella, M. E. (2014). Considerações sobre o clima e os recursos hídricos do semiárido nordestino. Caderno Prudentino de Geografia, 1(36), $126-142$. 